\title{
Research on Regional Differences and Influencing Factors of Energy Utilization Efficiency in China
}

\author{
Yunpeng Wang1, * \\ ${ }^{1}$ School of Business, Liao Cheng University, Liaocheng, 252000, China.
}

\begin{abstract}
Energy, as one of the important input factors in modern economic growth, plays a decisive role in the economic growth of all countries in the world. Use Moran I index and fixed effect model to measure the degree of spatial correlation and spatial difference between regions and analyze the influencing factors of energy efficiency, The results show that the energy efficiency of various provinces is spatially related, and the spatial distribution tends to be spatially concentrated; the per capita GDP has a significantly greater impact on the energy efficiency of the eastern region than it has on the western region; foreign direct investment (FDL) has an impact on the energy use of the eastern region There is a negative impact on efficiency and a positive impact on the efficiency of energy utilization in the western region; the number of patent grants has a significantly greater effect on the improvement of energy efficiency in the western region than in the eastern region; the increase in the proportion of the secondary industry has a positive impact on the energy use efficiency in the eastern region There is a positive impact and a negative impact on the energy efficiency of the western region.
\end{abstract}

Keywords: Energy efficiency, Moran I index, fixed effects model, regional differences.

\section{Introduction}

From the perspective of the economic field, energy, as one of the important input factors in modern economic growth, plays a decisive role in the economic growth of all countries in the world [1]. As a major energy country, China's total production and total consumption are among the top in the world, but my country's energy consumption per unit of output value is far higher than that of developed countries. With the implementation of the high-quality development strategy, the issue of energy constraints under the new development pattern has become increasingly prominent. Effectively improving energy utilization efficiency is the key to realizing the quality of economic development.

Obstacle supply, protection of the environment, and promotion of growth are the main goals facing energy problems. To achieve the above goals, improving energy efficiency is fundamental. The research on energy efficiency has always been a research hotspot of experts and scholars at home and abroad. Since my country's reform and opening up, energy use efficiency has improved significantly. Industrial structure, economic system, and degree of opening to the outside world are important factors that affect my country's energy use efficiency [2] (Stan, 2002). However, the spatial differences in energy use efficiency between regions are very obvious. And regional economic development has obvious cluster characteristics and spatial dependence [3] (Qiu Yanfang, Lu Yuhai, 2005). The inter-provincial differences in energy use efficiency in China are obvious, and coastal areas are significantly higher than inland areas, but research shows that the level of economic development There is no significant impact on regional energy use efficiency [4] (Qiu Ling et al., 2008). From the perspective of the regional energy system, the status quo of the region determines the energy use efficiency [5] (Liu Xiaoou, Ge Shaoyun, 2020). In the field of renewable energy, differentiation is adopted. Subsidies can improve the efficiency of renewable energy power generation [6] (Gao Jiangang, Yang Na, 2019). From the perspective of companies, corporate R\&D investment has a significant negative impact on corporate energy consumption intensity, that is, the increase in corporate R\&D investment can Promote the improvement of energy efficiency [7] (Ju Wei, 2021).

Most of them measure and analyze a certain energy efficiency from the perspective of regions or cities, and there are still few studies on the differences in energy efficiency in China. This paper attempts to apply spatial theory in economics to measure the regional differences and spatial correlations of energy efficiency in 27 sample provinces in China from 2005 to 2020, and use panel data to analyze the reasons for the differences in regional energy efficiency performance.

\section{Regional Differences in China's Energy Efficiency}

\subsection{Sample Selection}

Based on the availability of data and ensuring the accuracy of the data, this paper selects 27 provinces (cities, autonomous regions, hereinafter referred to as provinces) in China, except Tibet, Yunnan, and Hainan from 2005 to 2020. The data comes from "China Energy Statistical Yearbook" and "China Statistical Yearbook".

\subsection{Index Construction and Solution}

Theil entropy has the characteristics of dividing overall differences into differences between groups and differences within groups, and is often used in empirical research on overall differences and differences between regions [8] (Theil, 1967). This paper uses Theil entropy to calculate the difference in energy efficiency performance of various provinces, and the formula is:

$$
\text { Theil }_{t}=\frac{1}{N} \sum_{i=1}^{N} \frac{E F_{i, t}}{\mu_{t}} \operatorname{Ln}\left(\frac{E F_{i, t}}{\mu_{t}}\right)
$$


Among them, $E F_{i, t}=\frac{G D P_{i, t}}{E_{i, t}}$ and $\mu_{t}=\frac{1}{N} \sum_{i=1}^{N} E F_{i, t}$ are respectively the energy efficiency and energy consumption (in standard coal) of the $i$-th province in year $t$, and the GDP data is converted into 2005 constant prices. $\mu \mathrm{t}$ refers to the average energy efficiency of each province in year $t, N=27, t=1, \ldots, 16$. The larger the Theil entropy, the more uneven the distribution of observations. When the energy efficiency development level of each province is completely average, Theil entropy $=0$; In the most unbalanced case, Theil entropy $=\ln (27)=3.3322$. Using formula (1) to calculate the Theil entropy value in each year, the results show that before 2009, the Theil entropy value fluctuated greatly. Except for the decline in 2007 , the overall increase trend during the sample period. In 2010, the Theil entropy reached its highest point, and then began to decline, but the fluctuation was small, as low as 0.0830 in 2019, and rebounded again in 2020 . Therefore, in general, the regional differences in my country's energy efficiency are significant and maintained at a certain level.

There are differences in energy efficiency between regions, but is there a link between energy efficiency among regions? This article uses the Moran I index to measure the overall spatial correlation and spatial difference between regions, which is defined as:

$$
\text { Moran } I=\frac{\sum_{i=1}^{n} \sum_{j=1}^{n} W_{i j}\left(Y_{i}-\bar{Y}\right)\left(Y_{j}-\bar{Y}\right)}{S^{2} \sum_{i=1}^{n} \sum_{j=1}^{n} W_{i j}}
$$

Among them, $S^{2}=\frac{1}{n} \sum_{i=1}^{n}\left(Y_{i}-\bar{Y}\right)^{2}, \quad \bar{Y}=\frac{1}{n} \sum_{i=1}^{n} Y_{i}$, Yi is the observation value of the $\mathrm{i}$-th area, and $\mathrm{Wij}$ is the binary adjacency space weight matrix, which means that any element in it adopts the adjacency standard. The value range of Moran I index is $[-1,1]$, and 0 means that the distribution of location data has no correlation with the distribution of attribute values. When you want to test whether there is spatial autocorrelation in $n$ regions, you need to use the standardized statistic $Z$ value to test [9] (Anselin, 1988). The $\mathrm{Z}$ value is defined as:

$$
Z(d)=\frac{\text { Moran } I-E(I)}{\sqrt{\operatorname{VAR}(I)}}
$$

When the $Z$ value is positive and significant, the observations tend to be spatially clustered; when the $Z$ value is significantly negative, the observations tend to be spatially scattered. In formula (3), $E_{n}(I)=-\frac{1}{n-1}$, $\operatorname{VAR}(I)=\frac{n^{2} \omega_{1}+n \omega_{2}+3 \omega_{0}}{\omega_{0}^{2}\left(n^{2}-1\right)}-E_{n}^{2} \quad, \quad$ among them, $\omega_{0}=\sum_{i=1}^{n} \sum_{j=1}^{n} \omega_{i j} \quad, \quad \omega_{1}=\frac{1}{2} \sum_{i=1}^{n} \sum_{j=1}^{n}\left(\omega_{i j}+\omega_{j i}\right)^{2} \quad$, $\omega_{2}=\sum_{i=1}^{n}\left(\omega_{i .}+\omega_{. i}\right)^{2}$. According to the geographic location of each province, a spatial weighting matrix is constructed according to whether the 27 provinces are adjacent or not. The results calculated using equations (2) and (3) are shown in Table 1.

Table 1. Moran I index and statistical value

\begin{tabular}{ccccc|ccccc}
\hline Year & Moran I & E (I) & VAR $(\mathrm{I})$ & Z value & Year & Moran I & E (I) & VAR (I) & Z value \\
\hline 2005 & 0.5716 & -0.0083 & 0.0309 & 3.2979 & 2013 & 0.5765 & -0.0083 & 0.0309 & 3.3255 \\
2006 & 0.5175 & -0.0083 & 0.0309 & 2.9901 & 2014 & 0.5741 & -0.0083 & 0.0309 & 3.3122 \\
2007 & 0.5427 & -0.0083 & 0.0309 & 3.1338 & 2015 & 0.5234 & -0.0083 & 0.0309 & 3.0237 \\
2008 & 0.5177 & -0.0083 & 0.0309 & 2.9915 & 2016 & 0.5199 & -0.0083 & 0.0309 & 3.0040 \\
2009 & 0.4924 & -0.0083 & 0.0309 & 2.8477 & 2017 & 0.4910 & -0.0083 & 0.0309 & 2.8398 \\
2010 & 0.5149 & -0.0083 & 0.0309 & 2.9756 & 2018 & 0.4908 & -0.0083 & 0.0309 & 2.8381 \\
2011 & 0.5522 & -0.0083 & 0.0309 & 3.1873 & 2019 & 0.5049 & -0.0083 & 0.0309 & 2.9186 \\
2012 & 0.6023 & -0.0083 & 0.0309 & 3.4722 & 2020 & 0.4962 & -0.0083 & 0.0309 & 2.8691 \\
\hline
\end{tabular}

The results show that the Moran I index is all positive, indicating that the spatial distribution of energy efficiency in various provinces tends not to be completely random, and there is a spatial connection between the observed values. The results also show that the $Z$ value over the years is greater than the critical value of the normal distribution function at the $1 \%$ significance level (1.96), reflecting that the spatial distribution of energy efficiency in various provinces in my country tends to be spatially agglomerated. Therefore, accelerating the transfer of advanced technologies to backward regions is conducive to promoting the improvement of energy efficiency in various regions. The Moran I index value of energy efficiency is small, indicating that the spatial dependence of energy efficiency is relatively weak. The Moran I index has a maximum value of 0.6023 , which appeared in 2002, but afterwards it showed a downward trend. This shows that the energy efficiency of each province is less affected by its own space, but more affected by exogenous variables, indicating that the impact of other variables on energy efficiency is increasing.

\section{Analysis of Factors Influencing China's Energy Utilization Efficiency}

There are many factors influencing the performance of regional energy efficiency by economic activities. Based on previous research and own empirical research experience, and considering the availability of data, this article proposes possible influencing factors hypothesis.

\subsection{Theoretical Hypothesis}

Hypothesis 1: The level of regional economic development is positively correlated with energy efficiency.

Hypothesis 2: The amount of FDI introduced is positively correlated with energy efficiency. 
Hypothesis 3: The level of technological progress is positively correlated with energy efficiency. There is still a lack of consensus on the measurement standards of technological progress. This chapter uses the number of patent grants commonly used in various regions to reflect technological progress [10].

Hypothesis 4: The proportion of the secondary industry is negatively correlated with energy efficiency.

\subsection{Model Building}

Panel data can not only control unobservable variables and variables omitted in economic measurement, such as policy differences, cultural differences and consumption differences, etc.; it can also identify and measure some factors that cannot be identified by pure cross-sectional models and pure time series models. Combining the two can better reflect the relationship and dynamic characteristics of variables [11]. Its general form is:

$$
Y_{i t}=\alpha_{i}+\sum_{k=1}^{4} X_{i t k} \beta_{k}+\mu_{i t}
$$

Among them, $\mathrm{i}$ represents 27 provinces, $\mathrm{i}=1,2, \ldots, 27 ; \mathrm{t}$ represents time, $t=1,2, \ldots, 16 ; X_{\text {itk }}$ station represents the $k t h$ of the $i$-th province in the $t$-th year Independent variables; $\beta_{\mathrm{k}}$ represents the corresponding slope coefficient, and the error term satisfies $\mathrm{u}_{\mathrm{it}} \mathrm{N}\left(0, \sigma_{\mathrm{it}}\right)$. The panel data model has three types: variable intercept, variable coefficient, and same intercept and coefficient. In order to study the overall status of energy efficiency in various provinces and at the same time reflect the differences between provinces, this paper adopts the variable intercept model. If the model intercept is not zero from the time and cross section, and is the same constant, then the model equation (4) is a mixed estimation model. However, due to the significant structural changes in the energy efficiency of the provinces and regions during the sample period, the following hypotheses are proposed.

Assumption 1: $\mathrm{u}_{\mathrm{it}}=\mathrm{v}_{\mathrm{i}}+\mathrm{e}_{\mathrm{t}}+\varepsilon_{\mathrm{it}}$, where neither vi and et are random. The model under this assumption is called the fixed effects model.

Assumption 2: $\mathrm{u}_{\mathrm{it}}=\mathrm{V}_{\mathrm{i}}+\mathrm{e}_{\mathrm{t}}+\varepsilon_{\mathrm{it}}$, where both $\mathrm{v}_{\mathrm{i}}$ and $\mathrm{e}_{\mathrm{t}}$ are random. $\mathrm{E}\left(\mathrm{v}_{\mathrm{i}}\right)=0, \mathrm{E}\left(\mathrm{v}_{\mathrm{i}}^{2}\right)=0, \mathrm{E}\left(\mathrm{v}_{\mathrm{i}}^{2}\right)=\sigma \mathrm{v}^{2}, \mathrm{E}\left(\mathrm{e}_{\mathrm{i}} \mathrm{e}_{\mathrm{j}}\right)=0(\mathrm{i} \neq \mathrm{j}), \mathrm{E}\left(\mathrm{e}_{\mathrm{t}}\right)=0$, $\mathrm{E}\left(\mathrm{e}_{\mathrm{t}}{ }^{2}\right)=\sigma_{\mathrm{e}}{ }^{2}, \mathrm{E}\left(\mathrm{e}_{\mathrm{s}} \mathrm{e}_{\mathrm{t}}\right)=0(\mathrm{~s} \neq \mathrm{t})$. For all $\mathrm{i}$ and $\mathrm{t}$, vi and et and $\varepsilon_{\mathrm{it}}$ are not related, the model under this assumption is called the random effects model [12-16]. According to theoretical assumptions, the following model is established:

$$
\mathrm{EF}_{\mathrm{it}}=\alpha_{\mathrm{i}}+\beta_{1} \mathrm{GDP}_{\mathrm{it}}+\beta_{2} \mathrm{FDI}_{\mathrm{it}}+\beta_{3} \mathrm{Tec}_{\mathrm{it}}+\beta_{4} \text { Structure }_{\mathrm{it}}+\mathrm{u}_{\mathrm{it}}(5)
$$

Among them, EF is energy efficiency; GDP is per capita gross national product; FDI is foreign direct investment; Tec is the number of patents granted; Structure is the proportion of the secondary industry.

\subsection{Outcome of Practice}

\subsubsection{Data collection}

According to assumptions, the variable data of GDP, FDI and secondary industry value added are all from the "China Statistical Yearbook" and converted into constant prices in 2005. The three types of patents (inventions, utility models, and designs) application authorization data come from the "China Science and Technology Statistical Yearbook", and all variables are annual observations.

\subsubsection{Model estimation}

First, judge the pros and cons of the mixed-effects model, fixed-effects and random-effects models, and use Eviews 5.1 software to solve and verify the model. The formula is as follows:

$$
\begin{aligned}
& F=\frac{\left(S S E_{r}-S S E_{\mu}\right) /(T-1)}{S S E_{\mu} /(N T-T-1)} \\
& L M=\frac{N T}{2(T-1)}\left[\frac{T^{2} \overline{\hat{\mu}}^{\prime} \overline{\hat{\mu}}}{\hat{\mu}^{\prime} \hat{\mu}}-1\right]^{2}
\end{aligned}
$$

Among them, $\mathrm{F}$ is the overall significance level test, and LM is the Breusch-Pagan Lagrangian multiplier (LM) test[17]. SSEr and SSEu respectively represent the residual sum of squares of the constrained model (mixed estimation model) and the unconstrained model (individual fixed effects model at a time), $\mathrm{N}$ is the number of cross-sections, and $\mathrm{T}$ is the time span. $\overline{\hat{\mathrm{u}}} \overline{\hat{\mathrm{u}}}$ Represents the residual sum of squares calculated by the individual random effects model. $\hat{u}$ ' $\hat{u}$ The sum of squared residuals calculated for the mixed estimation model. According to formula (6), the F and LM statistics are 27.6 and 0.7037 , respectively. Under the $95 \%$ confidence level, the fixed-effect model and the random-effect model are accepted. Further according to Hausman test to determine whether to choose a fixed-effect model or a random-effect model, the Chi-Sq. value supports the use of a random-effect model, as shown in Table 2.

Table 2. Estimated impact of regional energy efficiency differences

\begin{tabular}{cccccc}
\hline Variable & Constant term & LNGDP & LNFDI & Tec & Structure \\
\hline \multirow{3}{*}{ Random effect } & -1.7623 & 0.245 & 0.0007 & 0.056 & -0.8583 \\
& -0.0692 & $(0.0113)^{* * *}$ & $(0.0055)^{* * *}$ & $(0.0071)^{* * *}$ & $(0.1296)^{* *}$ \\
& Sample size & F statistics & R-Squre & Hausman test \\
& 27 & 523.9712 & 0.8318 & Chi-Sq. & Statistic=30.9861 \\
\hline
\end{tabular}

Note: (1)The values in parentheses are standard deviations; (2)Asterisks $(* * *)$ and $(* *)$ indicate significant at the level of $1 \%$ and $5 \%$ (the same below)

When calculating according to the model formula (5), take the logarithm of GDP, FDI and the number of patents to eliminate or reduce the heteroscedasticity. From the results obtained in Table 2, the variable signs are consistent with the original assumptions, and all pass $5 \%$. The significance test.
Regional per capita GDP, FDI and the number of patents all have a positive impact on regional energy efficiency. Among them, GDP per capita has the greatest impact on energy efficiency, while the proportion of the secondary industry has a significant negative effect on energy efficiency. The individual characteristics of energy efficiency in each province that cannot be explained by variables in the model are shown in Table 3. For example, in Beijing, there are other factors that cause the intercept term to decrease from the 
overall level with a random effect of 0.3440 , while the random effect in Fujian Province causes the intercept term to increase by 0.3738 from the overall level. There are many reasons that affect the performance of individual eigenvalues in provinces. Since this problem is not the main research purpose of this article, we will not continue to explore it, but it provides a basis and reference for future research.

Table 3. Regional individual characteristic values of random effects

\begin{tabular}{cc|cc|cc|cc}
\hline Area & $\begin{array}{c}\text { Random } \\
\text { effect }\end{array}$ & Area & Random effect & Area & Random effect & Area & Random effect \\
\hline Beijing & -0.3440 & Shandong & 0.0377 & Heilongjiang & -0.0583 & Guizhou & -0.0300 \\
Tianjin & -0.1589 & Henan & 0.0810 & Shanghai & -0.1703 & Shaanxi & 0.0170 \\
Hebei & -0.0193 & Hubei & 0.0193 & Jiangsu & 0.1195 & Gansu & 0.0111 \\
Shanxi & -0.1440 & Hunan & 0.0453 & Zhejiang & 0.1420 & Qinghai & 0.0377 \\
Inner Mongolia & -0.1255 & Guangdong & 0.0931 & Anhui & 0.1423 & Ningxia & -0.0627 \\
Liaoning & -0.2866 & Guangxi & 0.2279 & Fujian & 0.3738 & Xinjiang & -0.1446 \\
Jilin & -0.1391 & Sichuan & 0.0366 & Jiangxi & 0.2606 & & \\
\hline
\end{tabular}

Due to the significant imbalance of economic development in the east and west regions of our country, this article further conducts a panel analysis on the energy efficiency influencing factors of these two regions (The division of regions changes with changes in the level of economic development and policy trends. Currently, the standard used by the National Bureau of Statistics to divide the east, middle, and west regions includes Beijing, Tianjin, Hebei, Liaoning, Shanghai, Jiangsu, Yaojiang, Fujian, Shandong, Guangdong, Guangxi, and Hainan are 12 provinces, autonomous regions, and municipalities directly under the Central Government. The central region includes 9 provinces and autonomous regions in Shanxi, Inner Mongolia, Jilin, Heilongjiang, Anhui, Jiangxi, Henan, Hubei, and Hunan; the western region includes Sichuan, Guizhou, Yunnan, Tibet, There are 9 provinces and autonomous regions in Shaanxi, Gansu, Ningxia, Qinghai and
Xinjiang. The western region has fewer samples after excluding departmental provinces due to the lack of some data, so it is classified into the central region and collectively referred to as the western region). According to the results of Hausman's test, the fixed-effects model is better than the random-effects model. The specific calculation results of the equation are shown in Table 4. Comparing the influence of variables in the eastern and western regions, it can be found that the impact of per capita GDP on the energy efficiency of the eastern region is significantly greater than that of the western region. This reflects that with the same economic growth, the energy efficiency of the eastern region is much higher. That is to say, compared with the eastern region, the western region relies on high energy consumption to achieve economic growth.

Table 4. Comparison of East and West Energy Utilization Efficiency Impacts Differences

\begin{tabular}{ccccc}
\hline \multirow{2}{*}{ Explanatory variables } & \multicolumn{2}{c}{ East area } & \multicolumn{2}{c}{ Western Region } \\
\cline { 2 - 5 } Constant term & Coefficient & Standard deviation & Coefficient & Standard deviation \\
LNGDP & -6.5183 & 0.6336 & -1.0734 & 0.3261 \\
LNFDI & 0.2661 & $0.1415^{* *}$ & 0.0781 & $0.0412^{* *}$ \\
Tec & -0.0069 & 0.0096 & 0.0597 & $0.0113^{* * *}$ \\
Structure & 0.0217 & $0.0077^{* * *}$ & 0.0475 & $0.0197^{* * *}$ \\
Sample size & 0.5941 & $0.1509^{* * *}$ & -0.2018 & $0.0943^{* * *}$ \\
F statistics & & 133.143 & 27 \\
R-Squre & 0.9661 & 25.1184 \\
Fixed effects and random & Chi-Sq. Statistic=1.3203 & Chi-Sq. Statistic $=16.3427$ \\
Effects Hausman's test & &
\end{tabular}

$* * *, * *$ indicate significant at $1 \%$ and $5 \%$ respectively

Contrary to the conclusions of the national model, the results show that the introduction of FDI in the eastern region has a negative effect on regional energy efficiency. The explanation that can be given is that the introduction of foreign capital in the eastern region of my country is more concentrated in high-energy-consuming industries, resulting in a greater increase in energy consumption. Economic growth has a negative impact on energy efficiency in the east. The introduction of FDI in the western region has promoted the improvement of energy efficiency. The possible reason is that the introduction of FDI in the western region is relatively small, and the positive spillover effect brought about economic growth greater than the increase in energy consumption, thus improving the energy efficiency of the region.

Therefore, when the eastern region introduces FDI, it is necessary to transform the industry structure. We should not only emphasize the amount of foreign investment, but also focus on the fields of FDI investment, and avoid the concentration of high energy-consuming industries. The western region should make full use of the existing spillover effects of FDI and accelerate the development of low-energyconsuming industries. Only by implementing differentiated energy policies from multiple perspectives for different regions can the overall goal of energy conservation and consumption reduction be achieved. The number of patent grants plays a significantly greater role in the improvement of energy efficiency in the western region than in the eastern region, and the former is nearly twice as effective as the latter. This shows that the western region has obvious advantages in improving energy efficiency through technological progress, and there is still great potential. The possible reason is that the technology of the western region lags behind that of the eastern region, and the gains from the improvement of unit 
technology level are still in the stage of increasing returns to scale.

Different from the national model coefficient, the increase in the proportion of the secondary industry in the eastern region has a positive impact on the improvement of energy efficiency, indicating that the development of the secondary industry in the eastern region of my country is tending to lower energy consumption. However, the increase of the secondary industry in the western region has reduced energy efficiency, indicating that the increase of the secondary industry in the western region is not conducive to the improvement of energy efficiency in the region, and the development of the secondary industry tends to be energyintensive.

\section{Analysis Conclusion}

This paper uses the Moran I index and fixed effects model to measure the degree of spatial correlation and spatial difference between regions and analyze the influencing factors of energy use efficiency with 2005-2020 as the research interval. The results show that the energy efficiency of various provinces is spatially correlated. The spatial distribution tends to agglomerate in space; the per capita GDP has a significantly greater impact on the energy efficiency of the eastern region than it has on the western region; foreign direct investment (FDL) has a negative impact on the energy efficiency of the eastern region and has a negative impact on the energy availability of the western region There is a positive impact on efficiency; the number of patent grants has a significantly greater effect on the improvement of energy efficiency in the western region than in the eastern region; the increase in the proportion of the secondary industry has a positive impact on the energy use efficiency in the eastern region, and it has a positive impact on the energy use efficiency in the western region. Negative influence.

To fundamentally improve my country's energy efficiency, we must unremittingly adjust the industrial and industrial structure, unremittingly optimize the energy structure, and unremittingly promote technological progress[18]. At the moment, we need to grasp the key points and treat both symptoms and root causes to further improve my country's energy efficiency and achieve my country's energy-saving and emission-reduction goals.

\section{References}

[1] Xu Qinhua, Liu Xu. Prospects for China's Energy Economy [M]. Renmin University of China Press: Renmin University of China Research Report Series, 2020 (12): 1-2.

[2] Shi Dan.Improvement of Energy Utilization Efficiency in the Process of my country's Economic Growth [J]. Economic Research,2002(09):49-56+94.

[3] Zou Yanfen,Lu Yuhai.Analysis of Regional Characteristics of Energy Utilization Efficiency in China Based on Spatial Autoregressive Model [J]. Statistical Research, 2005(10):6771.
[4] Qiu Ling,Shen Yuming,Ren Wangbing,Yan Tingting.Analysis of Regional Differentiation and Influencing Factors of Energy Utilization Efficiency in China [J]. Journal of Natural Resources,2008(05):920-928.

[5] Liu Xiaoou,Ge Shaoyun.The definition of energy efficiency of regional integrated energy system and its correlation analysis [J]. Automation of Electric Power Systems,2020,44(08):8-18.

[6] Gao Jiangang, Yang Na.Integrated policy tool to promote the development of China's renewable energy indust - taking wind energy industry as an example [J]. Mathematics in Practice and Understanding,2019,49(13):30-42.

[7] Ju Wei.Can corporate R\&D investment improve energy efficiency-micro empirical evidence from the energy consumption intensity of listed companies in China [J]. Friends of Accounting,2021(17):123-130.

[8] Theil H. The capital-energy substitutability debate: a new look. The Review of Economics and Statistics, 1967, 77 (3): 5669.

[9] Anselin L. Spatial Econometrics: Methods and Models. Dordrecht: Kluwer Academic Publishers, 1988, 34 (5): 574582.

[10] Sinton J E, Fridley D. What goes up: recent trends in China's energy consumption. Energy Policy, 2000(8)671-687.

[11] Ji Jianyue,Sun Yanan.Environmental Regulation, R\&D Investment and Green Technology Progress: An Empirical Analysis Based on China's Provincial Panel Data [J/OL]. Journal of Henan Normal University (Philosophy and Social Sciences Edition),2021(06):1-8.

[12] Ren Xueni,Luo Youxi.Random effect quantile regression model based on double SCAD penalty[J].Statistics and Decision,2021,37(18):9-13.

[13] Fan Shide, Jin Tongyao. Research on the Internal Mechanism and Effect of China's Labor Migration on Household PovertyAn Empirical Research Based on Panel Logit Model and Random Effect Model [J]. Jiangsu Social Sciences, 2020(06): 79-89+242- 243 .

[14] Liang Qi,Guo Xinwei,Shi Ning.Study on Early Warning of Small and Medium-sized Enterprise Financial Failure Based on Random Effect Logistic Model [J]. Journal of Management Engineering,2014,28(03):126-134.

[15] Shi Meijing. Random effect variance component model and its application-Quantitative analysis of the impact of stock turnover rate and industry factors on the rate of return $[\mathrm{J}]$. Journal of Shanxi University of Finance and Economics, 2002(01): 99-101.

[16] Zhang Hongxing,Jia Yandong.New Ideas Set by Panel Data Model - Unification of Fixed Effects and Random Effects [J]. Journal of Quantitative Economics and Technical Economics, 2006(06):148-154.

[17] Du Wenqin,Guo Shujuan.Research on my country's Green Energy Efficiency Improvement Path under the Dual-Carbon Target [J/OL]. Management Modernization, 2021(06):96-99.

[18] Wei Chu,Shen Manhong.Energy efficiency and its influencing factors: an empirical analysis based on DEA [J]. Management World,2007(08):66-76. 